\section{DA VOZ À LETRA}

FROM VOICE TO LETTER

\section{Eduardo Sterzi}

UNICAMP

Campinas, SP, Brasil

\begin{abstract}
Resumo
Momento decisivo na constituição da cultura literária moderna é aquele assinalado pela transição de uma poesia predominantemente oral para uma poesia predominantemente escrita. A forma do soneto, que emergiu na Itália do século XIII, desempenha papel decisivo nesta passagem e não por acaso Dante Alighieri partirá dela para propor, com sua obra, uma nova concepção de lírica, distinguida por uma seriedade intelectual que o trovadorismo desconhecia.
\end{abstract}

\begin{abstract}
A decisive moment in the formation of modern literary culture is that signaled by the transition from a predominantly oral poetry to a predominantly written poetry. The form of the sonnet, which emerged in thirteenth century Italy, plays a crucial role in this passage - and not by accident it is based on this form that Dante Alighieri proposes a new conception of lyric, distinguished by an intellectual seriousness that troubadourship did not know.
\end{abstract}

\section{Riassunto}

Momento decisivo nella constituzione della cultura letteraria moderna è quello segnato dalla transizione da una poesia prevalentemente orale a una poesia prevalentemente scritta. La forma del sonetto, la quale è stata inventata nell'Italia del secolo XIII, gioca un ruolo cruciale in questo passaggio e non per caso Dante Alighieri partirà di quella per proporre un nuovo concetto di lirica, marcato per una serietà intellettuale sconosciuta per il trovadorismo.

O soneto tem papel fundamental na superação do forçoso nexo música-poesia característico do trovadorismo e, portanto, na emergência de uma nova noção de lírica. ${ }^{1}$ Que o soneto con-

\footnotetext{
${ }^{1}$ Sobre a origem do soneto e o soneto como forma, cf. Leandro BIADENE, "Morfologia del sonetto nei secoli XIII e XIV", Studj di Filologia Romanza, IV, 10 (1888), pp. 1-234; Pio RAJNA, "Come nacque il sonetto", in Scritti di filologia e linguistica italiana e romanza, a cura di Guido Lucchini, Roma: Salerno, 1998, t. 2, pp. 772-777; Mario PRAZ, "Sonetto", in Enciclopedia Italiana, Roma: Istituto della Enciclopedia Italiana, 1950, pp. 141-143; Leo SPITZER, "Una
}

Palavras-chave: voz; escrita; poesia; lírica; soneto.

Keywords: voice; writing; poetry; lyric; sonnet.

Parole chiave: voce; scrittura; poesia; lirica; sonetto. 
* (SPINA, Segismundo. Iniciação na cultura literária medieval. Rio de Janeiro: Grifo, 1973: 24.) serve a reminiscência da música já na sua designação (sonetto não é outra coisa que "pequeno som”, "sonzinho") é um toque irônico de grande valor heurístico: a música, afinal, persistirá como arte secreta a pulsar por baixo - ou mesmo no cerne - de toda a lírica moderna (nesta revolução poética que o soneto pontua, a poesia, como bem disse Segismundo Spina, "deixa de ser cantada para se tornar cantável').* Mas vale assinalar que o paradoxo implícito na denominação do soneto não faz senão ecoar um paradoxo anterior e mais profundo, impresso na denominação do gênero: nascida do canto - acompanhado, presume-se, pela lira -, e por muito tempo ao canto subordinada, a lírica, à medida que se vai especializando no exame e na expressão da subjetividade, reluta cada vez mais em extinguir-se na música (de fato, o gênero, na modernidade, parece atingir sua maior eficácia exatamente na ausência de toda música exterior ao poema; aliás, muitas vezes, por uma deliberada anulação de qualquer ideia de música, de qualquer musicalidade, como ocorre em João Cabral). É, pois, como uma cicatriz de sua mais remota pré-história que a lírica continua a trazer a música em si ao menos como virtualidade; por mais obstinada que seja sua emancipação da música e da voz, por mais que se dirija a um estado de pura escrita, conserva sempre uma nostalgia da música e da voz, e em certa medida até do gesto que a vinculava à dança. Em seu

questione di punteggiatura in un sonetto di Giacomo da Lentino (e un piccolo contributo alla storia del sonetto)", Cultura Neolatina, XVIII, 1 (1958), pp. 61 70; Elias L. RIVERS, "Certain Formal Characteristics of the Primitive Love Sonnet”, Speculum, XXXIII (January 1958), pp. 42-55; Ernest Hatch WILKINS, "The Invention of the Sonnet", The Invention of the Sonnet and Other Studies in Italian Literature, Roma: Edizioni di Storia e Letteratura, 1959, pp. 11-39; Aldo MENICHETTI, "Implicazioni retoriche nell'invenzione del sonetto", Strumenti Critici, XXVI (febbraio 1975), pp. 1-30; Christopher KLEINHENZ, The Early Italian Sonnet: the First Century (1220-1321), Lecce: Milella, 1986; Cristina MONTAGNANI, "Appunti sull'origine del sonetto", Rivista di Letteratura Italiana, IV (1986), pp. 9-64; Pierre BLANC, "Sonnet des origines, origine du sonnet: Giacomo da Lentini”, in Yvonne BELLENGER (ed.), Le sonnet à la Renaissance des origines au XVII siècle: actes des troisièmes journées rémoises (17-19 janvier 1986), Paris: Aux Amateurs de Livres, 1988, pp. 9-18; Paul OPPENHEIMER, The Birth of the Modern Mind: Self, Consciousness, and the Invention of the Sonnet, New York and Oxford: Oxford University Press, 1989; Roberto ANTONELLI, "L"invenzione' del sonetto", in Miscellanea di studi in onore di Aurelio Roncaglia a cinquant'anni dalla sua laurea, Modena: Mucchi, 1989, v. 1, pp. 3575; Aurelio RONCAGLIA, "Note d'aggiornamento critico su testi del Notaro e invenzione del sonetto", in Giovanni RUFINO (a cura di), In ricordo di Giuseppe Cusimano: Giornata di Studio sul Siciliano Antico (17 dicembre 1991), Palermo: Centro di Studi Filologici e Linguistici Siciliani, 1992, pp. 9-25. 
tempo, Nietzsche ainda lamentará a separação entre poesia e música na lírica moderna: "a nossa lírica moderna parece a estátua de um deus sem cabeça”.* Esta nostalgia não é estranha aos próprios poetas, e a lírica moderna pode bem ser definida como palavra saudosa de ser música, justo por não poder mais sê-la. Com razão, Paul Zumthor pôs em dúvida a adequação da palavra literatura - em que o étimo littera se faz perceber com tanta nitidez - para denominar as manifestações poéticas medievais.* Não se trata de uma redução irrefletida e irresponsável da letra à voz, do manuscrito à performance, só para restituir valor, compensatoriamente, ao corpo por longo tempo reprimido ou ignorado, mas, sim, de afirmar a constatação de um "trânsito" comum a toda a "literatura" medieval: "todo texto poético ou ficcional, dos séculos IX e $\mathrm{X}$ até pelo menos o XIV, transitou pela voz, e este trânsito não foi aleatório. Mesmo composto por escrito e na paz de alguma cela, o texto comporta, inscrita nas suas profundezas, uma intervenção determinante, que age sobre ele como um poderoso fator de formalização: a intenção de se dizer [l'intention de se dire], quero dizer, de desabrochar [s'épanouir] num ato vocal". ${ }^{2 *}$ Pode-se mesmo sugerir que o típico poema lírico moderno é sempre uma espécie de alegoria formal da passagem da poesia musical-vocal para a poesia escrita, e, sendo assim, carrega sempre em si a tensão entre um código musical e um código gráfico - tensão que se declara de vez no prefácio do Un coup de dés, que, mal-comparando, está para a lírica de Mallarmé como a Vita Nova estava para aquela de Dante: salto para fora das formas estritamente líricas; operação a um só tempo poética e metapoética pela qual a lírica até então produzida é chamada à consciência de si mesma; retomada, perspectivação e superação da experiência lírica. ${ }^{3}$

\footnotetext{
${ }^{2}$ No magnífico sintagma "l'intention de se dire", não será demasiado ver algo como uma tradução de expressōes características da Vita Nova, como "disiderio" ou "volontà di dire". Mas não esqueçamos que a obra dantesca, sobretudo depois de sua estação estritamente lírica, se estrutura, já com a organização da Vita Nova, em torno de um conceito forte de livro.

${ }^{3}$ MALLARMÉ, Stéphane. "Préface" (a Un coup de dés). In: Igitur. Divagations. Un coup de dés, Paris: Gallimard, 1996: 405-407: "Les 'blancs', en effet, assument l'importance, frappent d'abord; la versification en exigea, comme silence alentour, ordinairement, au point qu'un morceau, lyrique ou de peu de pieds, occupe, au milieu, le tiers environ du feuillet: je ne transgresse cette mesure, seulement la disperse. [...] Ajouter que de cet emploi à nu de la pensée avec retraits, prolongements, fuites, ou son dessin même résulte, pour qui veut lire à haute voix, une partition. La différence des caractères d'imprimerie entre le motif prépondérant, un secondaire et d'adjacents,
}

* (NIETZSCHE, Friedrich. $O$ nascimento da tragédia: ou helenismo e pessimismo. Jacó Guinsburg (trad.). São Paulo: Companhia das Letras, 1996: 44.)

* (Cf. ZUMTHOR, Paul. "Y a-t-il une 'littérature' médiévale?", Poétique, LXVI (avril 1986): 131-139; A letra e a voz: a "literatura" medieval, trad. Amálio Pinheiro e Jerusa Pires Ferreira, São Paulo: Companhia das Letras, 1993.)

* (ZUMTHOR, Paul. "Y a-til une 'littérature' médiévale?", op. cit.: 131.) 
Dante, no De vulgari eloquentia, ao mesmo tempo em que postulava a superioridade das palavras da canção em relação à música que porventura as acompanhasse (do que depreendia ser essa música prescindível), frisava a necessidade de ainda dispor as palavras com vista à sua harmonização musical:

Preterea disserendum est utrum cantio dicatur fabricatio verborum armonizatorum, vel ipsa modulatio. Ad quod dicimus quod nunquam modulatio dicitur cantio, sed sonus, vel thonus, vel nota, vel melos. Nullus enim tibicen, vel organista, vel cytharedus melodiam suam cantionem vocat, nisi in quantum nupta est alicui cantioni; sed armonizantes verba opera sua cantiones vocant, et etiam talia verba in cartulis absque prolatore iacentia cantiones vocamus. Et ideo cantio nichil aliud esse videtur quam actio completa dicentis verba modulationi armonizata: quapropter tam cantiones quas nunc tractamus, quam ballatas et sonitus et omnia cuiuscunque modi verba sunt armonizata vulgariter et regulariter, cantiones esse dicemus. *

Ademais, é preciso discutir se se chama canção a fabricação de palavras harmonicamente dispostas, ou a modulação em si. Ao que dizemos que a modulação nunca é dita canção, mas som, ou tom, ou nota, ou melodia. Por certo, nenhum flautista, ou organista, ou citaredo chama canção à sua melodia, a não ser na medida em que está casada a uma canção, enquanto os harmonizadores de palavras chamam canções à sua obra, e, assim, às palavras em folhetos, ${ }^{4}$ mesmo na ausência de alguém que as recite, chamamos cançôes. E por aí se vê que a canção não é nada senão uma ação em si completa de quem diz palavras harmonizadas por modulaçôes: por isso, tanto às cançôes, de que agora tratamos, quanto às baladas e aos sonetos e a todas as sequências de palavras que são harmonizadas seja em vernáculo ou em língua regular, chamamos cançōes. ${ }^{5}$

dicte son importance à l'emission orale et la portée, moyenne, en haut, en bas de page, notera que monte ou descend l'intonation. [...] Aujourd'hui ou sans présumer de l'avenir qui sortira d'ici, rien ou presque un art, reconnaisons aisément que la tentative participe, avec imprévu, de poursuites particulières et chères à notre temps, le vers libre et le poème en prose. Leur réunion s'accomplit sous une influence, je sais, étrangère, celle de la Musique entendue au concert; on en retrouve plusieurs moyens m'ayant semblé appartenir aux Lettres, je les reprends".

${ }^{4}$ Desde pelo menos a época dos trovadores, os poemas eram, em sua maioria, compostos já por escrito, e não improvisados oralmente, e sua primeira difusão se dava na forma de folhas volantes - rotuli -, que eram carregados em sacos pelos jograis (cf. AVALLE, D'arco Silvio. I manoscritti della letteratura in lingua d'oc. Torino: Einaudi, 1993: 61). A persistência dessa difusão avulsa e precária é a base material da prática stilnovista de enviar poemas aos amigos, à espera de respostas que esclareçam o significado, ou, melhor, que o façam ampliar-se.

${ }^{5}$ Cf. DURLING, Robert M. e MARTINEZ, Ronald L. Time and the Crystal: Studies in Dante's Rime Petrose, Berkeley, Los Angeles and Oxford: University of California Press, 1990: 21: "In fact in Italy there had almost certainly never been a 
No mesmo tratado, Dante define a poesia como "fictio rethorica musicaque poita" (II iv 2). É uma expressão bastante difícil de traduzir: algo como "ficção retórica composta em música" - mas a rara palavra latina "poita" significa algo mais do que o que exprime o termo português "composta". No Convivio, tratado em vernáculo cuja primeira fase de redação é mais ou menos contemporânea à preparação do De vulgari eloquentia, a poesia é conceituada perifrasticamente como "cosa per legame musaico armonizzata" (I vii 14). Nesta definição, o adjetivo italiano "musaico" também não pode ser vertido meramente como "musical". "Poita" vem de "poire", forma latina medieval do verbo grego "poiein" ("fazer"), ou seja, o mesmo étimo de poesia. É muito provável que Dante o tenha encontrado no seu léxico de predileção, as Magnae derivationes de Uguccione da Pisa, onde se lê:

Poio, pois, poivi, poitum, idestfingo, is, unde hic poeta, tae, idestfictor, et proprie carminis alta verba loquens [...]. Item a poeta, poetor, aris carmina et poemata facere vel componere. Item a poio hic poetes, tis quaedam forma vel figura, et haec poesis illud idem, et poesis ipsa ars poetandi vel figmentum. Vel poesis est materia totius carminis, in qua poeta versatur. Vel poesis est opus multorum librorum sed poema, tis quod similiter derivatur a poio est proprie opus unius, licet generaliter pro opere accipiatur poete. ${ }^{6}$

Seria mais exato, portanto, apesar de soar bem mais estranho, traduzir o sintagma como "ficção retórica poetizada conforme a música", em que a conformidade prescinde da musicalização efetiva. O mesmo se dá com o "legame musaico" no Convivio: identifica uma concatenação musical que é inerente ao próprio poema, dispensando qualquer acompanhamento musical.

direct connection between the writing of a canzone and the composition of its musical setting, such as there had been - in theory, at any rate - in Provence." As referências de Dante à estrutura musical da canção, como notam Durling e Martinez, "retain the literary awareness of a connection between lyric poetry and song" (Ibidem: 22).

${ }^{6}$ Cito a partir do verbete poesia, redigido por Alfredo SCHIAFFINI para a Enciclopedia dantesca, Roma: Istituto della Enciclopedia Italiana, 1996, v. 4: 565; ver também, do mesmo autor, "'Poesis' e 'poeta' in Dante e nel medioevo", in Mercanti, poeti, un maestro, Milano e Napoli: Ricciardi, 1969: 46-48. Cf. PICONE, Michelangelo. "Vita Nuova" e tradizione romanza". Padova: Liviana, 1979: 12: "poita, adattamento medievale del greco Tाoıाı, in cui è da additare l'etimologia stessa di 'poeta': rappresenta la realizzazione concreta della fictio, l'inserimento di questa in un organismo letterario, e quindi l'atto stesso, fondamentalissimo, di poetare". O mesmo verbo é utilizado por Dante no último verso de sua segunda égloga latina: "ille quidem nobis, et nos tibi, Mopse, poymus" (que se pode traduzir por "ele isto a nós, e nós a ti, Mopso, cantamos"). 
* (FRIEDRICH, Hugo. Epochen der italienischen Lyrik, Frankfurt am Main: Vittorio Klostermann, 1964: 33; Epoche della lirica italiana, v. 1: Dalle Origini al Quattrocento. Luigi Banfi e Gabriella Cacchi (trad.). Bruscaglioni, Milano: Mursia, 1974: 31.)
*(BIADENE, Leandro. "Morfologia del sonetto nei secoli XIII e XIV", op. cit.: 4.)
A lírica moderna se enamora, inutilmente, pela música ou, fazendo-se investigação e reflexão, pelo silêncio. Forma eminentemente reflexiva, o soneto só nos fala, desde sua primeira floração siciliana, de uma emoção que passa pelo pensamento, em contraste com o convencionalismo emocional das cançōes provençais. Se é possível supor que o paralelismo, processo fundamental de toda a poesia "primitiva", deriva, em alguma medida, do ritmo do trabalho corporal' (e o que são as danças, com as quais o fenômeno poético, enquanto fenômeno rítmico, está originariamente ligado, senão metáforas - e, portanto, deslocamentos e subversões - do trabalho?), podemos também sugerir que, na lírica moderna, o ritmo do trabalho intelectual, muito mais fluido, é que se torna definidor da forma. Por isso, em substituição ao paralelismo como princípio da poesia, surge uma forma complexa como a do soneto, que se desenvolve ao modo de um silogismo, como imitação de um processo lógico (e isto mesmo quando, por exemplo com Mallarmé, a lógica mesma é posta em xeque). ${ }^{8}$ Hugo Friedrich define o soneto precisamente como "silogismo lírico" (lyrischer Syllogismus) - "se não sempre, ao menos na maioria dos casos".* Mas a reflexividade inerente à forma do soneto vai além da estruturação silogística. Considere-se, por exemplo, a descrição da forma por Leandro Biadene; aos seus olhos, o soneto aparece, desde sua gênese, como uma trama de pausas, uma edificação com espaços reservados para que ali se instalem a reflexão e a autoconsciência:

Desde o princípio, o Soneto consta de 14 decassílabos, e aparece dividido em duas partes principais, a primeira de oito versos, a segunda de seis. Raríssimas vezes, porém, esta divisão ou não existe ou mal se percebe. Na primeira parte, tem lugar uma pausa lógica ao fim de cada parelha, e a pausa depois da segunda parelha é comumente, mas não sempre, um pouco mais forte que as outras duas. Na segunda parte, a pausa principal cai depois do terceiro verso, de modo que esta segunda parte fica dividida em dois tercetos. Deve-se, porém, notar que em alguns dos sonetos mais antigos esta última pausa é muito suave, e em outros os últimos seis versos pareceriam quase dividir-se em três parelhas.*

\footnotetext{
${ }^{7}$ Cf. SPINA, Segismundo. Na madrugada das formas poéticas, São Paulo: Ática, 1982: 43-44.

${ }^{8}$ Cf. OPPENHEIMER, Paul. The Birth of the Modern Mind, op. cit.; PAZ, Octavio. "Stéphane Mallarmé: o soneto em ix". In: Signos em rotação. Sebastião Uchoa Leite (trad.). São Paulo: Perspectiva, 1996: 185-200.
} 
E, mais especificamente, levemos em conta a intuição fundamental de Amalia Cecere de que, em alguns sonetos da Vita Nova, os tercetos constituem uma reflexão em relação ao que é apresentado nos quartetos:* o que nos permite sugerir que, em alguma medida, a forma mesma da Vita Nova, em sua eficaz combinação de poesia e comentário, pode ser não mais do que uma expansão metapoética - metaformal - da forma do soneto.

O soneto é, pois, muito importante para que se conquiste para a poesia aquela dimensão de seriedade intelectual que o trovadorismo não conhecia. "O soneto", já o disse André Jolles, "não nasceu e não podia nascer com os Provençais, tampouco com os Minnesänger alemães. Na poesia dos trovadores como naquela dos Minnesänger permanece ainda um eco do canto e da roda como formas da repetição".* Embora, na Itália, a música e a dança não estivessem menos presentes do que nos demais territórios europeus, é ali que, pela primeira vez em âmbito vernacular, se produz "uma forma fechada e exclusivamente literária que se liberta de uma vez por todas da música e do movimento do corpo".* Isto tem a ver, certamente, com todo um contexto que propicia a emergência das primeiras noçōes fortes de indivíduo e de interioridade. E a dissolução do nexo entre palavra e música faz-se de fato acompanhar da subjetivização e individualização da palavra. Porque antes se acentuava um nexo pré-subjetivo, que era sobretudo corporal (o corpo, por definição, é o lugar onde a alma não está; a circunscrição da alma é a circunscrição de um "locus [...] qui non est locus", ' e será mesmo, acrescente-se, no extremo do Moderno, a de um lugar onde não se está: "estou sofrendo lá dentro, onde não estou", ${ }^{*}$ a subjetividade impõe-se de início pela negação do corpo. No entanto, este processo não é linear: e a lírica ducentista bem pode consistir, em algumas de suas maiores realizações, num mapeamento do corporal, num levantamento dos vínculos espirituais entre corpo e alma. Não é por acaso que a passagem de uma poesia da voz a uma poesia da letra, em fins da Idade Média, se faça acompanhar, como se vê de modo exemplar na Vita Nova, de uma crescente reivindicação de coincidência entre poesia e vida, texto e experiência. Essa reivindicação, que independe da possibilidade ou não de se verifi-

\footnotetext{
${ }_{9}^{9}$ Confessiones XIII 9, 2. In: MIGNE, Jacques Paul (ed.), Patrologiae cursus completus, series latina. Paris: Ateliers Catholiques, 1844-1864 (de agora em diante, referida apenas como PL), 32. Cf. Enarrationes in Psalmos IX 15, in PL 36, 124 : "Locus [...] animae non in spatio aliquo est".
}

* (CECERE, Amalia. "La struttura del sonetto nella Vita Nuova". In: SIMONELLI, Maria Picchio (a cura di) Beatrice nell'opera di Dante e nella memoria europea 1290-1990: atti del Convegno Internazionale (10-14 dicembre 1990). Firenze: Cadmo, 1994: 100.)

* (JOLLES, André. "La visione d'amore nella Vita nuova". In: I travestimenti della letteratura: saggi critici e teorici (1897-1932). Silvia Contarini e Roberta Zuppet (trad.). Milano: Bruno Mondadori, 2003: 28.)

* (Idem)

* (ALEXANDRE, António Franco. Visitação. Porto: Gota de Água, 1982: 59.) 
* (ZUMTHOR, Paul. "La cultura della voce". Alberto Vàrvaro (trad.). In: BOITA$\mathrm{NI}$, Piero; MANCINI, Mario e VÀRVARO, Alberto (diretto da). Lo spazio letterario del Medioevo: il Medioevo volgare, v. 1: La produzione del testo, t. 1, Roma: Salerno, 1999: 139.)
* (ZUMTHOR, Paul. "Y a-t-il une 'littérature' médiévale?", op. cit.: 137-138.) car os vínculos entre versos e fatos, surge justamente como contrapartida de um novo quadro de recepção dos poemas em que não se tem mais, diante do público, a presença corporal do poeta ou de um intérprete a validar o poema. Já as vidas e razos occitânicas - que, não esqueçamos, foram os modelos textuais prosaicos cronologicamente mais próximos da Vita Nova-provavelmente tiveram a função de encaminhar o sentido dos poemas quando estes eram apresentados fora de seu local e momento de produção, uma espécie de compensação pela ausência do autor. É esse laço entre transição da voz à letra e reivindicação da coincidência poesia-vida que explica o porquê dessa reivindicação ser paralela a um movimento textual que pode lhe parecer contraditório, movimento rumo a uma crescente autonomia do texto poético.

A própria leitura, nesta época, era concebida e praticada de modo muito diferente de como hoje o fazemos. A leitura era, como observa Zumthor, "a ruminação de uma sabedoria”.* A identificação de cada palavra como uma entidade separada, sua decifração, era um ato de razoável lentidão, devido às condições materiais da grafia. Ruminatio, segundo a orientação monástica para a leitura: no mínimo um murmúrio (os movimentos faciais deixavam clara a semelhança com o ato de nutrição), mas muitas vezes a vocalização em voz alta acompanhava a leitura, pelo menos até o século XVI. Vivia-se, afinal, numa cultura em que a presença da escrita era rara; só com a proliferação dos escritos impôs-se a leitura silenciosa. Já a partir do século XIII, entre os homens cultos, lia-se em silêncio. No século XIV, mas com mais força a partir do XV, as universidades estabeleceram regulamentos para as bibliotecas abertas aos estudantes, exigindo o silêncio na leitura. As consequências dessa nova situação da escrita e da leitura para a hermenêutica são bem descritas por Zumthor:

O texto literário é fechado [clos]: tanto em virtude do ato que, materialmente ou idealmente, o encerra [referme], quanto na intervenção de um sujeito que efetua este fechamento [clôture]. Mas tal fechamento provoca o comentário, suscita a glosa, de modo que, a este nível, o texto se abre, e um dos traços próprios da "literatura" é sua interpretabilidade. $\mathrm{O}$ texto tradicional, por sua vez, pelo simples fato de que ele transita pela voz e pelo gesto, não pode ser senão aberto, de uma abertura primária, radical, a ponto de, às vezes, escapar, por instantes [par éclairs], à linguagem articulada: é por isso que ele se esquiva à interpretação, pelo menos a toda interpretação global.* 
A nova literatura - a literatura propriamente dita - exige uma hermenêutica que não só lhe é paralela, mas muitas vezes, como se pode ver exemplarmente na Vita Nova, é incorporada ao texto primário (borrando a própria distinção entre textos primários e secundários); por sua vez, a poesia anterior, de base vocal, reclamava, em sentido etimológico, uma estética, ou mesmo uma erótica, ${ }^{10}$ apta a captar os valores sensíveis (sensuais) da voz e do gesto que lhe são definidores. Dois editores e tradutores recentes da Vita Nova, Dino S. Cervigni e Edward Vasta, chamaram a atenção para a necessidade de se levar em consideração a sobrevivência da oralidade no primeiro livro de Dante: "Por um lado, [...] a obra está repleta de evidência de consciência oral [oral consciousness]".* Mas logo acrescentam:

Por outro lado, a Vita nuova está simultaneamente e autoconscientemente dirigida para a expansiva cultura letrada do século treze. Letramento [literacy] e literatura, fundadas na palavra escrita, governam o projeto autoral definitivo da obra, que é elevar um dialeto do italiano vernacular, já amplamente escrito, a padróes de arte e expressão comparáveis àqueles da poesia latina escrita [...]. A obra oferece não memórias inalteradas, mas memórias autoconscientemente transcritas; ela encaminha [addresses] o tema todo da escrita, da narrativa à glosa a várias formas poéticas; e ela introduz inovaçôes (tanto em forma como em conteúdo) em tradições prévias e tendências correntes de produção literária. A obra encaminha um mundo literário; ela está repleta de referências literárias, alusões e empréstimos; e ela registra a produção e circulação de determinados poemas escritos. Diferentemente da externalidade dos materiais em produçôes orais, os materiais da Vita nuova são aqueles de uma cultura letrada: interiores, interpretativos, centrados na autoconsciência individual.*

A obra de Dante, situando-se na confluência da tradição oral e da escritura emergente - mas, sobretudo, promovendo ativa-

\footnotetext{
${ }^{10}$ Quando falo em erótica, estou pensando em conhecidas propostas teóricas de Roland BARTHES (Le plaisir du texte) e de Susan SONTAG (Against interpretation) - mas, deliberadamente, extrapolo o quadro histórico a que ambos pretendiam aplicá-las. Se, para Barthes e Sontag, uma erótica da arte, em substituição a uma hermenêutica, parecia adequar-se sobretudo ao texto moderno e pós-moderno, a meu ver ela parece mais adequada no que toca a 'textos' pré-modernos, em que a parte do corpo é essencial. Note-se que Sontag refere-se explicitamente a Dante no ensaio que dá o título ao seu livro: "Outrora (digamos, para Dante), era quem sabe revolucionário e criativo executar obras de arte de modo que pudessem ser experimentadas em vários níveis. Agora não é mais" "Contra a interpretação". In: Contra a interpretação. Ana Maria Capovilla (trad.). Porto Alegre: L\&PM, 1987: 22.).
}

*(CERVIGNI, Dino S. eVAS TA, Edward. "From Manuscript to Print: The Case of Dante's Vita Nuova". In: Theodore J. CACHEY Jr. (ed.), Dante Now: Current Trends in Dante Studies, Notre Dame and London: University of Notre Dame Press, 1995: 84.

* (Ibidem: 85) 
* (VALÉRY, Paul. "Je disais quelquefois à Stéphane Mallarmé...". In: Varieté III, IV et V. Paris: Gallimard, 2002: 29.)

* (AHERN, John. “The Reader on the Piazza: Verbal Duels in Dante's Vita Nuova". In: Texas Studies in Literature and Language, XXXII, 1 (Spring 1990): 19.) mente a passagem de uma a outra, sem jamais silenciar de vez essas vozes que ganham sobrevida espectral, porém não menos efetiva, neste corpus absoluto -, propõe, portanto, uma exigência dupla e, em certa medida, paradoxal: que a hermenêutica não prescinda da percepção sensível - física, corporal - proporcionada por uma erótica do texto; e que esta erótica não desdenhe a penetração intelectual - consciente, mental - oferecida pela hermenêutica. Ignorar essa dupla exigência - que, frise-se, é historicamente determinada e, assim sendo, não pode ser estendida, sem cautela, a qualquer outra produção artística - tem sido a receita mais segura para o fracasso da crítica perante a obra dantesca. A volatilização do eros, sempre salientada na poesia stilnovista ou depois em Petrarca, explica-se, ao menos em parte, pela superação de uma fase físico-corporal da poesia, mais do que por qualquer pudicícia religiosa. Mas algo daquela corporeidade sempre permanece, nem que seja pelas metáforas corporais para designar a linguagem e o poema: um erotismo, pois, do próprio texto. Valéry já observou, pensando em Mallarmé, que "a Poesia é toda pagã: ela exige imperiosamente que não haja nenhuma alma sem corpo - nenhum sentido, nenhuma ideia que não seja o ato de alguma figura notável, construída de timbres, de duraçôes e de intensidades" (la Poésie est toute païenne: elle exige impérieusement qu'il n'y ait point d'âme sans corps - point de sens, point de idée qui ne soit l'acte de quelque figure remarquable, construite de timbres, de durées et d'intensités).* Seja como for, é de fato a poesia como escrita, e não mais como canto, que se impõe com o soneto, a despeito de possíveis sobrevivências. A originalidade da obra dantesca se justifica em larga medida por essa prevalência da escrita: "a originalidade de Dante, como ele e outros a viram, consistiu em parte em reconhecer a poesia como um ato de comunicação escrita antes que puramente falada e em explorar as possibilidades que a escrita lhe proporcionou".* Compreensível, pois, que, agente de uma tal mutação cultural e não só poética, Dante faça a imagem da produção de poesia, em sua própria obra, oscilar entre a oralidade e a escritura. Se bem que a Vita Nova encene exatamente esta passagem de uma tecnologia da palavra para outra: em pelo menos dois momentos do libello, a superação da poesia medieval - oral, performática - se representa na forma da substituição do habitual verbo “dire”, usado para referir-se à composição 
do poema, por "scrivere": "scrivere parole rimate" (VN6.7 [XIII 7]) e "scrivere per rima" (VN 15.6 [XXIV 6]). ${ }^{11}$

É o stil novo todo, já com Guinizzelli, que, ao apropriar-se do legado trovadoresco, o supera com uma intensidade bem maior do que aquela da reação siciliana aos modelos provençais: precisamente porque o stil novo invoca o trovadorismo num ambiente em que as motivações sociopolíticas daquela poesia já não existem mais, sequer como resquícios. Precisa, pois, o stil novo, criar toda uma ética fantasmagórica, sem substância concreta, para preencher este vazio sob a forma. A lírica provençal operava por metáforas extraídas do mundo da religião e do cavaleirismo feudal: "natural" e mesmo "lógico", pois, que os "poetas burgueses", que sucederam aos trovadores, obliterem os aspectos da "metáfora feudal" que já "não respondiam a uma experiência viva" e, em compensação, confiram relevo à "metáfora religiosa". ${ }^{12}$ (Será, por isso, errôneo ver neste procedimento os sinais de alguma guinada mística no tratamento da matéria amorosa - somente na obra de Dante, em especial na Commedia, algo semelhante a isto ocorrerá.)

Contudo, a metáfora religiosa supõe uma base prévia, o sujeito e sua vida. Com Dante, como bem viu Auerbach, a "retórica" guinizzelliana, pela qual se expressavam sobretudo estados de espírito, é substituída pelo "evento concreto".* Aí estaria, para Auerbach, uma das fontes da potência da voz lírica de Dante em relação às demais vozes da época. E há ainda, a reforçar esta potência, a estrutura da frase: na sua poesia, "o pensamento é tão articulado que se faz melodia”.* Contini, nesta linha, enfatizou como ninguém a experiência (mas experiência que logo se faz supraindividual) como elemento distintivo entre o stil novo e a poesia anterior, a experiência que se imporá, pois, como componente crítica da narrativa da Vita Nova, assinalando o nascimento intelectual da forma:

${ }^{11}$ Domenico DE ROBERTIS (Il libro della "Vita Nuova", 2a ed. accresciuta, Firenze: Sansoni, 1970: 186n) observa que o verbo "scrivere" raramente é específico para designar composição poética, sendo mais usualmente empregado para referir-se a correspondência com amigos, e mesmo sendo diferenciado explicitamente de dire parole (a "autêntica operação poética", segundo De Robertis): "mi venne uno pensero di dire parole, quasi per annovale, e scrivere a costoro li quali erano venuti a me" ([XXXIV 3]). É utilizado ainda para designar o ato de transcrição dos poemas no libello.

${ }^{12}$ Os termos são de Aurelio RONCAGLIA, no ensaio "Precedenti e significato dello 'Stil Novo' dantesco" (In: Dante e Bologna nei tempi di Dante, a cura della Facoltà di Lettere e Filosofia dell'Università di Bologna, Bologna: Comissione per i Testi di Lingua, 1967: 22-23).

* (AUERBACH, Erich. Dante, poeta do mundo secular. Raul de Sá Barbosa (trad.). Rio de Janeiro: Topbooks, 1997: 55.)

* (Idem) 
* (CONTINI, Gianfranco. Letteratura italiana delle origini. Firenze: Sansoni, 1970: 298.)
A radical diferença entre o Stil Novo e a poesia precedente (em sentido largo, "siciliana") é que esta, enquanto poesia de amor, é puramente ritual, ligada a uma convenção temática e não a uma ocasião histórica, enquanto o Stil Novo deriva as suas situações da experiência: com a ressalva de que a experiência do indivíduo humano é súbito transportada ao homem em geral. Instaura-se, de tal modo, um duplo registro, em virtude do qual o eu é ao mesmo tempo o sujeito delimitado de uma ação e o homem universalmente considerado (por exemplo, e em particular, o amante de sempre); também os fatos internos, espirituais, são representados como movimentos em um processo de personificação. Tal simbolismo torna árdua ao leitor moderno a compreensão dos poemas stilnovistas e em geral das modalidades de escrita [delle scritture] em que a figuração substitui aquela que segundo o nosso costume seria análise psicológica: o simbolismo, óbvio para a mente medieval devido à componente platônica da cultura cristã, é uma defesa perene [uno schermo perenne], que foi recuperado para a inteligência direta e para a exegese reflexa somente por uma corrente do Romantismo e especialmente das escolas pós-românticas. Se os objetos são eles mesmos e outra coisa, também os fatos são eles mesmos e outra coisa: neste último caso, surge o exemplo da exegese bíblica, a qual por séculos se empenhara em distinguir do sentido literal, sempre consistente (a Bíblia é em primeiro lugar um livro histórico), outros sentidos "alegóricos" ou "místicos" (a tradição seguida por Dante, para além daquele propriamente alegórico, reconhece, pelo menos de modo intermitente, um "moral” e um "anagógico" ou relativo aos Novíssimos, ao destino último do homem). Estamos na estrada que conduz à polissemia da Commedia; mas, por enquanto, a passagem do simbolismo dos objetos àquele dos acontecimentos [eventi] é a passagem das poesias da Vita Nuova, com os seus enunciados relativamente contraídos [contratti], à prosa da Vita Nuova, em que a verdade se alinha narrativamente, historicamente. A Vita Nuova liga as suas duas componentes não simplesmente se estabelecendo como prosimetrum ao modo, sobretudo, de Boécio, mas se oferecendo, o que vai muito mais longe e é tão mais preciso, como um romance acompanhado por um comentário. Desse modo, aquilo que é, se não realmente a primeira narração, por certo o primeiro romance no vernáculo do sì [volgare di sì: perífrase para a língua italiana], a partir do modelo, como foi justamente observado, das vidas dos santos, ou, antes, das santas, tem, porém, um nascimento altamente intelectual, ao qual preside eminentemente a atividade crítica.*

A transição do século XIII ao XIV, sobretudo na França e na Itália (isto é, no espaço central da România), assiste à crise do modelo social e literário elaborado no sul da França - nesta já lendária Provença - e que ficou conhecido como a cultura do amor cortês. Este modelo persistira por dois séculos, mas agora sucumbia 
ao desgaste de sua própria fixidez, ao empobrecimento pela repetição do modelo, à dispersão depois da perseguição aos cátaros, que resultara na transferência de tantos trovadores para a Itália setentrional. Este é o cenário no qual se dá aquele processo dúplice que Corrado Bologna designou como "o eclipse do Trovador, a aurora do Poeta".* Com a discrepância entre o modelo cortês, que persiste ainda fantasticamente na poesia, e a nova realidade política e cultural da civilização burguês-comunal, ambicionam-se "formas de literariedade orgânicas ao projeto democrático-citadino"* e que possam superar as relações feudais de mecenato. Sinal da crise: o último grande trovador occitânico, Guiraut Riquier, em 1274 ou 1275 (ou seja, nos anos da infância e dos estudos de Dante, anos do primeiro encontro com Beatrice), envia documento a Alfonso $\mathrm{X}$ de Castela pedindo ao rei que diferencie entre "joglars" e "trobadors".* (Mas não se esqueça que o primeiro trovador conhecido, Guilherme IX de Aquitânia, brincava fazendo-se investir da persona do jogral.) É precisamente Dante que, neste quadro de desvalorização da figura do trovador, depois da falência da tentativa de restabelecer em outras bases o modelo cortês no círculo em torno a Frederico II, promove a figura do poeta. Esta já surge como figura mítico-heróica. Sua descrição por Bologna é certeira: "Saturnino, solitário, consoante às problemáticas do próprio tempo mas não necessariamente ligado a 'escolas' ou 'grupos', capaz de uma idealidade literária de fôlego larguíssimo expressa em linguagem sublime e original, porém comunicável em dimensóes socialmente amplas, o Poeta foge agora a qualquer dependência de mecenas ou senhores que signifique o desnaturamento e a sujeição da própria inspiração 'universal'”.* Como nota Bologna, é a própria forma do serventes, do poema "servil", "a serviço de", que o poeta tal como assumido por Dante contesta radicalmente. ${ }^{13}$ No entanto, alguns elementos do passado inevitavelmente persistem, porém submetidos a novas exigências. Se a prática da cortesia definia o universo trovadoresco provençal, ${ }^{14} \mathrm{o}$ ideal da cortesia - sua simulação num quadro social

\footnotetext{
${ }^{13}$ A lírica moderna, eminentemente desinteressada, começa de fato quando o poeta não sabe mais como responder de imediato à questão "para que serve a poesia?". A identidade entre Canto e Amor, que se anuncia nos trovadores para atravessar toda a lírica italiana e moderna, desdobrando-se naquela identidade complementar entre Canto e Morte, que em Dante encontrou sua formulação modelar, é uma espécie de tentativa de resposta - inconclusiva, por certo - a esta questão.

${ }^{14}$ Para uma definição de "cortesia" a partir da etimologia, cf. Georges DUBY, "O Roman de la Rose". In: Idade Média, idade dos homens: Do amor e outros ensaios,
}

* (BOLOGNA, Corrado. "Figure dell'autore nel Medioevo romanzo". In: BOITA$\mathrm{NI}$, Piero; MANCINI, Mario e VÀRVARO, Alberto (diretto da). Lo spazio letterario del Medioevo: il Medioevo volgare, v. 1: La produzione del testo, t. 1, Roma: Salerno, 1999: 339.

* (Ibidem: 340$)$

* (CF. BERTOLUCCI PIZZORUSSO, Valeria. "La Sup plica di Guiraut Riquier e la risposta di Alfonso X di Castiglia", Studi mediolatini volgari, XIV (1966): 11-135; BOLOGNA, Corrado. "Figure dell'autore nel Medioevo romanzo", op. cit.: 340 .)

* (BOLOGNA, Corrado "Figure dell'autore nel Medioevo romanzo", op. cit. 341$. 
em que ela não se estriba mais em relações concretas - definirá o universo stilnovista e, portanto, dantesco. ${ }^{15}$ Este ideal é essencial para a definição de novas concepções de subjetividade e individualidade, a começar pelo fato de que, agora, a nobreza independe do sangue: a nova "nobreza" do burguês tem como valores supremos a ética e a destreza com as palavras. ${ }^{16}$

A nova situação histórica comportava mesmo a criação de um novo público para esta poesia, público assim descrito por Dante, no Convivio, ao discorrer da necessidade de um comentário em vernáculo em vez de em latim:

[...] dico che manifestamente si può vedere come lo latino averebbe a pochi dato lo suo beneficio, ma lo volgare servirà veramente a molti. Ché la bontà dell'animo, la quale questo servigio attende, è in coloro che per malvagia disusanza del mondo hanno lasciata la litteratura [i.e. a escrita e a leitura em latim] a coloro che l'hanno fatta di donna meretrice; e questi nobili sono principi, baroni, cavalieri e molt'altra

trad. Jônatas Batista Neto, São Paulo: Companhia das Letras, 1989: 67: “'Cortesia': vamos partir desse termo românico e dos dois termos latinos dos quais ele deriva. Um, curtis, designa a residência nobre no centro de um grande domínio; o outro, curia, um 'parlamento', um grupo de homens reunidos em torno de seu chefe para discutir com ele, ajudá-lo, por meio de conselhos, a resolver as questôes comuns. O encontro desses dois vocábulos reflete bastante bem o que foi o feudalismo, que se enraíza ao mesmo tempo no senhorio rural e na companhia militar".

${ }^{15}$ Cf. ANTONELLI, Roberto. "Dante Alighieri”. In: Storia e antologia della letteratura italiana, v. 2: La poesia del Duecento e Dante, Firenze: La Nuova Italia, 1974, p. 203: "Le esperienze cortesi europee sono così filtrate, col Cavalcanti, oltre il Cavalcanti, attraverso le città mercantili dell'Italia centrale, vengono sostanziate della nuova problematica filosofico-scientifica e dei fermenti comunali (mai espliciti, ma sempre chiaramente presupposti, sì che per certi versi pare assurdo parlare di distacco dalla realtà anche per questa fase dell'attività dantesca) e sono quindi riespresse attraverso una figura sociale particolare tutta tesa, attraverso la generalizzazione ideologica della propria funzione, a creare un tipo umano ideale, a legittimare, attraverso la 'naturalità' di una supremazia spirituale, la 'naturalità' dell'ascesa sociale di una classe e quindi di un'organizzazione particolare della società". - Dante, no soneto Savere e cortesia (dirigido a Dante da Maiano), enumera os elementos que serão característicos do stil novo, e que servem ainda de resumo da cortesia: " $\mathrm{Sa}$ vere e cortesia, ingegno ed arte, I nobilitate, bellezza e riccore, I fortezza e umiltate e largo core, I prodezza ed eccellenza, giunte e sparte, I este grazie e vertuti in onne parte / con lo piacer di lor vincono Amore" (Rime 4a [XLVII]).

${ }^{16}$ Desenvolvendo assim, por certo, posições já avançadas pela cultura cortês, elaborada sobretudo por subalternos em contraposição aos nobres que lhes encomendavam trabalhos. Cf. ANDRÉ CAPELÂO. Tratado do amor cortês. Ivone Castilho Benedetti (tradução a partir da tradução francesa de Claude Buridant). São Paulo: Martins Fontes, 2000: 26 e 44-45. 
nobile gente, non solamente maschi ma femmine, che sono molti e molte in questa lingua, volgari, e non literati. *

*(Conv. I ix 4-5)

A conclusão de Auerbach, a partir de detalhada análise dos momentos em que o poeta se dirige ao leitor na Commedia, é de que "Dante criou um público não só apenas para si mesmo mas também para seus sucessores. Ele moldou, como leitores potenciais de seu poema, uma comunidade que provavelmente não existia na época em que ele o escreveu e que foi gradualmente estabelecida por seu poema e pelos poetas que vieram depois dele". Terracini, tendo lembrado essa observação de Auerbach, nota que, na prosa da Vita Nova - "ora diálogo, ora relato" -, "este público Dante o evoca, na verdade, como parte de si mesmo”. ${ }^{17 *}$ Percepção magnífica da futuridade da operação dantesca: criar uma literatura que ainda não há é também criar um público para esta literatura, e este público só pode começar por si, por uma circunscrição inicial à própria subjetividade, condizente com a nova seriedade conferida à poesia.

Eduardo Sterzi é professor de Teoria Literária na Universidade Estadual de Campinas (UNICAMP). É autor dos livros de estudos literários Por que ler Dante e A prova dos nove: alguma poesia moderna e a tarefa da alegria, assim como de Prosa e Aleijāo (ambos de poesia) e Cavalo sopa martelo (teatro). Organizou Do céu do futuro: cinco ensaios sobre Augusto de Campos. Dirige para a Dobra Editorial a coleção Exercícios de Leitura, dedicada à literatura brasileira contemporânea em seus mais diversos gêneros e formas. E-mail: <eduardosterzi@gmail.com>

\footnotetext{
${ }^{17}$ Ao que se acrescenta: "Nella prosa non vi sono apostrofi al lettore che lascino intravvedere che si è stabilita fra il poeta e chi ode o legge una relazione qualsiasi. Non vi è che uno spirito di partecipazione e di tacita intesa".
}

* (AUERBACH, Erich. Literary Language and Its Public in Late Latin Antiquity and in the Middle Ages. Ralph Manheim (trad.). Princeton: Princeton University Press, 1993: 312.)

* (TERRACINI, Benvenuto. "La prosa poetica della 'Vita nuova'. In: Analisi stilistica: teoria, storia, problemi, Milano: Feltrinelli, 1975: 216.)

Recebido em $15 / 06 / 2012$ Aprovado em 25/08/2012 